\title{
Income Convergence in a Rural, Majority African-American Region ${ }^{+}$
}

\author{
Buddhi Gyawali, Rory Fraser, James Bukenya, and John Schelhas*
}

ABSTRACT: This paper revisits the issue of income convergence by examining the question of whether poorer Census Block Groups have been catching up with wealthier Census Block Groups over the 1980-2000 period. The dataset consists of 161 Census Block Groups in Alabama's west-central Black Belt region. Estimates of a spatial lag model provide support for the conditional convergence hypothesis and explain roughly 60 percent of the variation in income growth. Income growth was positively and significantly correlated with education and employment, and negatively and significantly correlated with majority AfricanAmerican population.

Key Words: African-Americans; Alabama; Rural Income; Income Convergence

JEL Classifications: O12, O15, R12

\section{INTRODUCTION}

Neoclassical growth theory states that cross-sectional dispersion of per capita incomes in a region tend toward homogeneity over time, as poorer economies grow at faster rates than wealthier economies (Solow, 1956; Barro and Sala-i-Martin, 1991). Studies of income convergence in smaller, rural geographic areas may prove to be consistent with neoclassical growth theories, especially when more discrete, sub-county level data are analyzed. Most likely, conditional rather than absolute convergence may account for variations in ethnically diverse rural areas. Some researchers (e.g. Sherwood-Call, 1996; Hammond, 2006) found divergence in income among the nonmetropolitan regions and mixed evidence of convergence in metropolitan regions and states. The majority of income convergence/divergence research in the United States has focused on aggregated multi-county or multi-state data (Rey and Janikas, 2005). There are few studies using disaggregated data because of the limited availability of nonmetro data at the sub-county level in population censuses prior to 2000. In this paper, three fundamental questions about income convergence in an ethnically diverse, rural region are explored: (1) Do per capita incomes converge absolutely or conditionally? (2) Are changes in incomes correlated with changes in demographic and industrial factors? (3) Are spatial effects influencing income growth?

In the pursuit of the above objectives, we explore the spatial characteristics of the factors associated with income growth by following the empirical framework of Mankiw, Romer, and Weil, (1992), Sala-i-Martin (1996), and Rey and Montouri (1999). The factors influencing

\footnotetext{
${ }^{+}$The authors thank anonymous reviewers of the manuscript for their suggestions and comments. We also thank USDA Forest Service, the Alabama Agricultural Land Grant Alliance (AALGA), and the National Science Foundation (NSF) for providing financial support of the study.

* Gyawali and Fraser are affiliated with the Center for Forestry and Ecology, Alabama A\&M University. Bukenya is affiliated with the Department of Agribusiness, Alabama A\&M University. Schelhas is affiliated with USDA Forest Services, Tuskegee University.

Corresponding Author: Buddhi Gyawali, P.O. Box 1927, Alabama A\&M University, Normal AL 35762, Phone: (256) 372-4571, Email: buddhi.gyawali@aamu.edu.

(C) Southern Regional Science Association 2010.

ISSN 1553-0892

SRSA, 1601 University Avenue, PO Box 6025, Morgantown, West Virginia 26506-6025, USA.
} 
conditional income convergence are explained after considering the spatial interactions of incomes, employment growth, educational level, and demographics (population density, race, and age structure) across Alabama's west-central region. Three points make this paper unique: (1) the period of study (1980-2000), which corresponds to time following implementation of post-civil rights and welfare reforms as well as rural economic restructuring policies in the area; (2) the level of analysis, which focuses on U.S. Census Block Groups and is the first known attempt to use data at the sub-county level in nonmetropolitan counties of the southern United States; and (3) the accounting for spatial effects by using empirical spatial models.

The paper begins with a review of literature. In this section, we outline the theory of income convergence and divergence and simultaneously discuss the disequilibrium effects of concentration vis-à-vis the theory of cumulative causation, endogenous growth, and industry agglomeration. These theoretical discussions are then linked to economic restructuring efforts in the southern U.S., especially in nonmetro counties. We follow this with brief discussions of the study area, the level of analysis, and specifications of aspatial and spatial empirical models. The results are presented and discussed with regard to the findings of previous studies. The paper closes with a presentation of our conclusions.

\section{LITERATURE REVIEW}

\subsection{Income Convergence}

Income convergence has become a prominent theme in current regional macroeconomic and microeconomic research (Rupasingha, Goetz, and Freshwater, 2002; Lim, 2003; Lynch, 2003; Connaughton and Madsen, 2004; Marcouiller, Kim, and Deller, 2004; Nissan and Carter, 2005; Hammond, 2006). As first espoused by Solow (1956) and expanded on by Baumol (1986) and Sala-i-Martin (1996), income convergence is a long-term tendency towards the equalization of per capita incomes across geographic areas. This convergence results from faster income growth in areas with below-average per capita income than in areas with above-average per capita income (Rey and Janikas, 2005). Empirical studies at the multi-state and national levels have since provided evidence of this phenomenon. ${ }^{1}$ For instance, Lynch (2003) found that over a twelve-year period, average family income converged across the United States. Convergence happens once the equilibrium process ensures a steady-state growth path, assuming constant returns to scale (Loewy and Papell, 1996). ${ }^{2}$ During the equilibrium process, the short-run differences in regional growth rates that primarily result from differences in production technologies will equalize gradually when production factors (labor and capital) begin to freely flow among regions, thus equalizing the values of their marginal products. This becomes evident at a point in time when there exists a negative relationship between initial levels of per capita income and rates of income growth.

There has been little evidence of absolute income convergence in the United States, as most of the recent regional studies have found mixed results. Hammond (2006) found that nonmetropolitan regions in the United States are diverging from U.S. average income levels, while metropolitan regions show mixed evidence of divergence during the 1969-2001 period.

\footnotetext{
${ }^{1}$ Crown and Wheat (1995), Latzko (2002), Rupasingha, Goetz, and Freshwater, (2002), Lim (2003), and Lynch (2003) have provided evidence of income convergence in the United States.

${ }^{2}$ Equilibrium state is defined as a situation of uniform utility such that there are no incentives for further movement of labor markets and capital to ensure uniform profit (Molho, 1995).
}

(C) Southern Regional Science Association 2010. 
Sherwood-Call (1996) argues that the divergence observed in many U.S. states in the 1980s was primarily due to the plunge in oil prices in the post-oil crisis period. Other explanations for divergence or income inequality are endogenous growth processes, geographic spillovers, or agglomerations (Myrdal, 1957; Aghion and Howitt, 1997; Janikas and Rey, 2005; Bathelt, 2006).

A common premise of these theories is that regional growth tends to be "spatially sticky" because of cumulative causation processes whereby initially privileged regions accrue higher benefits (Lim, 2003; Janikas and Rey, 2005). Under these conditions, regional growth patterns do not reflect decreases in inequalities; instead they display greater disparities - a positive correlation between regional inequality and growth - which is evidence of divergence (Pritchett, 1996; Janikas and Rey, 2005; Yamamoto, 2008). Evidence in support of this theory can be found in empirical results (Crown and Wheat, 1995; Drennan, Tobier, and Lewis, 1996; Latzko, 2002; Hammond, 2006). These studies found a lack of consistency in income convergence across the U.S. due to the lack of uniformity in the attributes needed for equilibrium processes.

Studies in which divergence in income growth were revealed have suggested a number of plausible explanations. For example, Ngarambe, Goetz, and Debertin, (1998) suggest that inconsistent short-term and long-term economic restructuring measures in political units differentiate the steady state attributes of these units. That is, when short-term shocks affect regional labor markets, supply and demand of raw materials, and capital, they also impact incomes in sub-regional units, thereby opening a space for disequilibrium to occur. Disequilibrium effects on the concentration of resources in a specific geographic area create disparities in jobs and incomes. This is evident in natural resource-dependent regions such as mining areas in the Appalachians and the timber industries in the Cumberland Plateau and Black Belt regions (Joshi, Bliss, and Bailey, 2000; Rupasingha, Goetz, and Freshwater, 2002). These industries display limited spillover effects into the regional economy (Lopez-Bazo, Vaya, and Artis, 2004; Rey and Janikas, 2005).

To sum up the above arguments, we posit that the adjustment process of disequilibrium effects are consistent with cumulative causation theory (Kim, 1998), and it prevails as a result of interactions between exogenous and endogenous factors. That is, when technological progress is associated with knowledge generation, this creates favorable socioeconomic conditions (human, industrial, and financial capital) as well as climatic conditions (such as rich amenities, quality of life, housing prices), and discourages outmigration (Marcouiller, Kim, and Deller, 2004; Albrecht and Albrecht, 2007). Endogenous technological progress gathers momentum gradually and consequently helps to create and stabilize the demands for labor and resources internally. ${ }^{3}$ This process leads to self-propelled growth of economies, ensures long-run economic growth, and reduces income gaps across the region. From this perspective, similarity in endogenous rural characteristics such as demographics, and labor and industrial structures and resources increases the likelihood of similarly distributed income across the region (Rey and Janikas, 2005).

The persistence of unemployment, lower wages, and low mobility of workers (characteristics of many rural counties in the southern United States), may be due to the inability of these regions to absorb specific shocks, be they from the demand or supply side (McLaughlin and Stokes, 2002; Albrecht, Albrecht, and Murguia, 2005). However, neoclassical theory

\footnotetext{
${ }^{3}$ The endogenous growth model is used as an alternative to the Solow model to characterize the cross-country variations in income convergence. This model assumes non-decreasing returns to the set of factors of production and expects that regions with higher savings rates can grow faster indefinitely. Therefore, all regions do not need to converge in per capita income, even if they have the same preferences and technology (Aghion and Howitt, 1997).
}

(C) Southern Regional Science Association 2010. 
suggests that in the long run, adjustment processes begin gradually and differences in unemployment, human capital, and income growth will level off across the region. This process ultimately provides a favorable pathway for income convergence.

\subsection{Economic Restructuring in Rural America}

There is a general agreement that economic development of the United States came about as a result of economic restructuring as exemplified by the move from an agrarian society of the pre-World War II period to an industrial society in the post-World War II period to the current post-industrial society (Crown and Wheat, 1995; Kim, 1998; Lynch, 2003; Albrecht and Albrecht, 2007). Nonmetropolitan counties were similarly affected. Many of these counties relied heavily on specialization in farming, mining, and primary processing and were linked to the global economy (Hammond, 2006). Economic restructuring in the post-civil rights era, welfare reform, and the environmental stewardship period of the 1960s and 1970s yielded incentives, subsidies, tax reliefs, cost-shares, and increased investments in human, financial, and built capital development in an effort to achieve economic integration of rural areas into the larger (global) economy. These measures also helped to ease the pressures of commodity price competition and rising farm costs and discouraged migration from rural to urban areas. In broad terms, the goals were to increase capital accumulation in rural counties and to set them on a path to becoming industrial economies (Crown and Wheat, 1995; Kim, 1998).

Economic restructuring was successful in transforming the economies of a few rural southern counties. For example, technological development increased the productivity of farmers and encouraged them to operate larger farms with higher efficiencies (Kim, 1998; Albrecht and Albrecht, 2007). The rise in gross incomes and the decline in poverty in rural counties were evidence of this transformation (Yamamoto, 2008).

However, these positive effects of transformations still do not match the rate of economic growth enjoyed by metropolitan counties (Hammond, 2006; Albrecht and Albrecht, 2007). Time series analyses of incomes from 1969 to 2001 have shown that incomes of nonmetro regions have been consistently below average income levels of the U.S. (Hammond, 2006). Therefore, the expectation that short-term technological changes would decrease the long-term rate of return to capital and lead to convergence has not yet been realized in rural counties (McLaughlin and Stokes, 2002; Nissan and Carter, 2005).

Causes for disparity in metropolitan and nonmetropolitan counties have been traced to differences in demographics, education, employment, and other measures of economic performance. Changes in demographic structures, employment, and education occurred when rural youths migrated to metropolitan areas in search of jobs and better education (Crown and Wheat, 1995; Marcouiller, Kim, and Deller, 2004; Albrecht, Albrecht, and Murguia, 2005). The rates of labor movement from southern to northern states have increased since the 1980s because of stagnant wages in the rural south and the wage gap between southern and northern states (Tolnay, 2003; Albrecht, Albrecht, and Murguia, 2005; Hammond, 2006). The rate of growth of service sector jobs in rural areas has not kept pace with income growth nor has it reduced income inequality (Snyder and McLaughlin, 2004). In addition, technological advances have reduced the demand for labor (Crown and Wheat, 1995; Ngarambe, Goetz, and Debertin, 1998; Albrecht and Albrecht, 2007).

Spatial disparities in employment and agglomeration of industries resulted from manufacturing industries' preferences for locations with easy access to raw materials,

(C) Southern Regional Science Association 2010. 
infrastructure, and a cheaper labor market (RSS Task Force, 1993; Gibbs and Bernat, 1997; Goetz and Rupasingha, 2002). Industrial development strategies were premised on the prevailing assumption that raw (primary) material processing would attract secondary processors and service providers, thereby employing surplus labor and increasing local incomes. This agglomeration effect was further assumed to create interdependence between industry, the local natural resources, and the local labor pool in order to reduce long-run production costs. However, nonmetropolitan counties (mostly from the southern United States) have not been able to catch up with the growth rate enjoyed by other counties; this has been a subject of research for many years (Loewy and Papell, 1996; Rupasingha, Goetz, and Freshwater, 2002; Albrecht, Albrecht, and Murguia, 2005).

How have economic restructuring approaches rooted in neoclassical growth theory impacted the rural south? On the one hand, researchers have found that macro-level economic restructuring policies in the forms of economic integration, removal of trade barriers, and reduction of taxes have led to a divergence in industrial structures and incomes. On the other hand, the proponents of neoclassical growth theory argue that economic restructuring inevitably leads to a convergence in incomes. This paper offers a framework to explore this anomaly in one of the poorest regions of the country, Alabama's west-central region, where substantial efforts were made to restructure the economy and reduce poverty in the past several decades. The major findings of previous studies in the southern United States suggest rising income inequality between African-Americans and whites, inadequate educational infrastructure, loss of manufacturing jobs, and high rates of youth outmigration despite economic restructuring efforts (McLaughlin and Stokes, 2002; Rupasingha, Goetz, and Freshwater, 2002; Snyder and McLaughlin, 2004).

This study attempts to fill this gap by conducting research at the sub-county level by including an analysis of geographic factors and the effects of spatial interactions on income change. Evidence of income convergence in regional-level studies has focused either on the state or county levels, but no work has been done at the Census Block Group (CBG) level. ${ }^{4}$ Analysis at this level may indicate a relatively higher role of endogeneity, which creates non-ideal equilibrium conditions according to neoclassical growth theory. More recent studies have provided evidence of the importance of including the spatial interaction of labor markets, income distribution, infrastructure, and demographic factors at finer geographic scales (Lim, 2003; Rey and Janikas, 2005). In this paper, we utilize data that are less aggregated than county or state level data, which are more commonly used. We also take account of spatial interaction effects to provide more robust and reliable inferences.

\section{DESCRIPTION OF STUDY AREA AND DATA}

The area chosen for this study consists of eight counties in the west-central region of Alabama: Dallas, Greene, Hale, Lowndes, Marengo, Perry, Sumter, and Wilcox (see Figure 1).

\footnotetext{
${ }^{4}$ The most recent evidence of using sub-county level census data is by Crandall and Weber (2004), who used Census tract data to study spatial concentrations of poverty.
}

(C) Southern Regional Science Association 2010. 
FIGURE 1. Study Area Showing the Eight Counties, Major Towns and 161 CBGs in the West-Central Region of Alabama

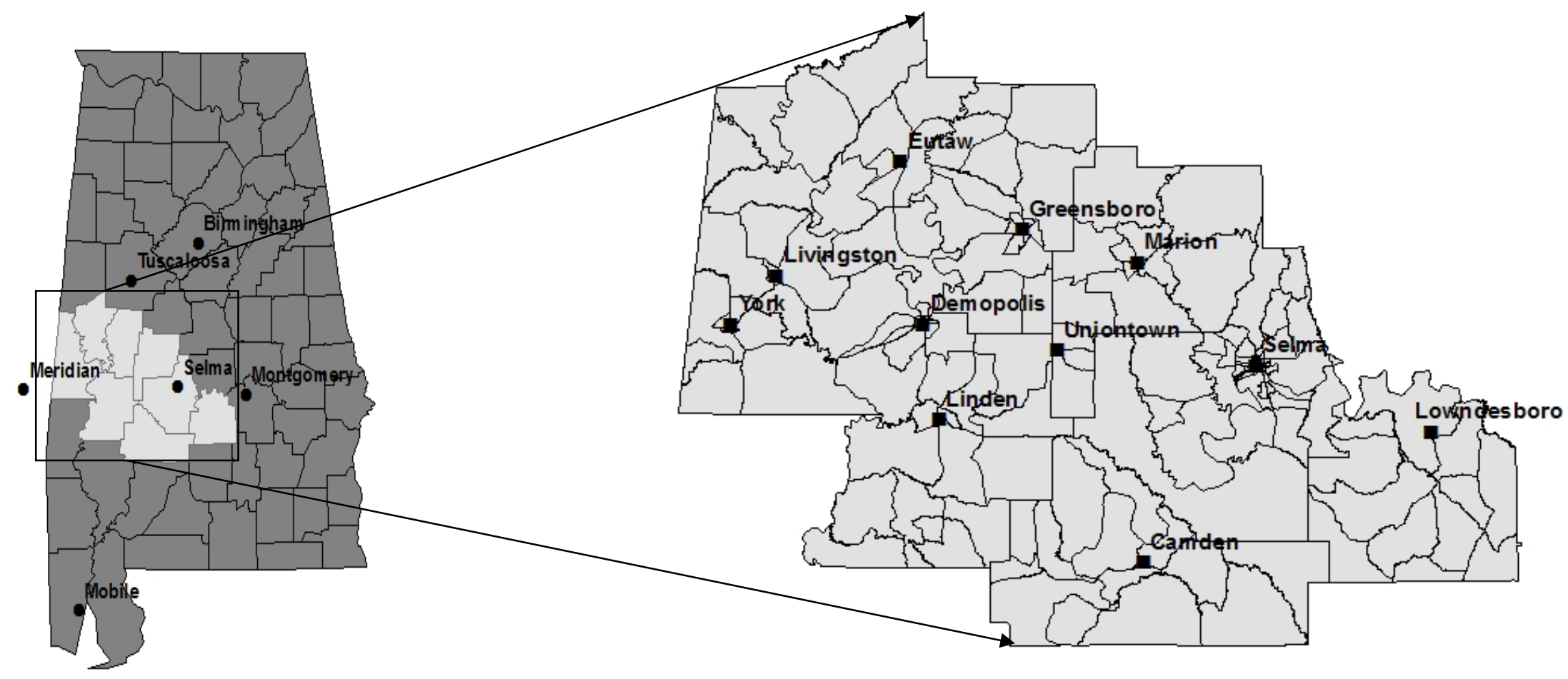


These counties were selected because they represent the largest contiguous group of Alabama counties in which there is a majority (greater than 50 percent) African-American population in each county.

In this "majority-minority" study area there are many economically and racially segregated communities differentiated by disparities in income, population distribution, resource allocation, and human capital development (Schelhas, Zabawa, and Molnar 2003). Over the past century, as the rest of the South, the economy has shifted from being agrarian and forest-based to a more industrial-based economy (Joshi, Bliss, and Bailey, 2000). Infestation of cotton by the boll weevil in 1917 and the collapse of the stock market in 1929 devastated the agrarian economy, which never fully recovered despite reforms in agricultural and land management policies in the 1940 to 1960 period. However, a spate of state and federal economic restructuring efforts was initiated in the 1960s and 1970s as a positive outcome of new voting rights, welfare reform, and environmental stewardship. By 1980, the agrarian economy of Alabama had given way to an industrial economy.

Economic restructuring in the region between 1960 and 2000 has affected labor markets and the regulation of forest and agricultural activities. It has shifted agrarian jobs to manufacturing and service jobs and led to the formation of manufacturing, human, industrial, and financial capital. The availability of cheap labor, raw materials, access to waterways, ports, and major national highways enticed forest-based industries and automobile plants into the region (Joshi, Bliss, and Bailey, 2000). Two major auto-manufacturing plants (Mercedes-Benz and Hyundai) are within a 50 mile radius of the study region and now generate 10 percent of the state's manufacturing gross state product. In 2003, the auto industry in Alabama accounted for 96,200 jobs, of which two-thirds are in southern Alabama (Auto Alliance, 2003).

Alabama contains the nation's second largest area (21.6 million acres) of commercial forest. There are 167 primary forest manufacturing facilities in the state; of these, 98 are sawmills, 19 are plywood or veneer mills, and 14 are pulp and paper mills (Alabama Forestry Commission, 2007). Much of this forest is located in Alabama's west-central region, which was expected to grow faster due to higher paying industrial jobs, capital accumulation, and human capital development (Joshi, Bliss, and Bailey, 2000).

The Black Belt counties of west-central Alabama are of special interest because of the majority presence (67 percent) of African-Americans (compared with 26 percent in Alabama as a whole). One can assume that after the significant civil rights and welfare reforms of the 1960s, African-Americans wield their highest level of political and administrative influence in the state in this eight county area, and therefore individually or collectively have a greater likelihood of achieving equal or higher levels of economic growth in the region. This is especially relevant in Alabama, a "no home rule" state, wherein economic development initiatives are controlled at the state level (with some exemption granted to larger municipalities, none of which are in the study area).

U.S. Census data from 1980 and 2000 for all 161 census block groups (CBGs) in the eight counties of the west-central region of Alabama were used (Geolytics, 2004). The CBG is the lowest unit for which the U.S. Census Bureau makes its data available to the public. Typically, CBGs range between 600 and 3,000 people, with an optimum size of 1,500 people (U.S. Census Bureau, 2007). Compared to larger geographical units, CBGs tend to be relatively homogeneous internally with respect to demographics, economic status, and living conditions.

(C) Southern Regional Science Association 2010. 
The geographic boundaries of CBGs may change from one census to another. Data available for these units are not suitable for comparative analysis over time unless they are normalized to maintain the same boundaries in each census. Recently, Geolytics Inc. made available the 1980 census data normalized (weighted) to the 2000 boundaries and these data have been widely used for comparative study (Crandall and Weber, 2004). ${ }^{5}$

\section{MODEL SPECIFICATION}

The objective of this study is the estimation of spatial models of income convergence between 1980 and 2000. The basic empirical model is a modification of the one specified by Barro and Sala-i-Martin (1991), which controls for differences in the steady state conditions of each unit in a region. The underlying hypothesis is that the economic growth in each unit follows a path of economic transformation influenced by an array of both endogenous and exogenous factors. Endogenous factors, such as development of human capital as a result of internal processes within the study area, are expected to drive economic growth by developing new skills and technology, as well as efficient and effective means of production. At the same time, exogenous factors such as technology transfers influence economic growth in the region.

Six endogenous and exogenous factors appear consistently in previous studies of conditional income convergence: (1) population structure, (2) education, (3) employment, (4) industry, (5) urban centers, and (6) spatial spillover effects. In this study, initial levels and changes in population density, share of the population under 15 years old, race, education, industrial jobs and firms are included (Tables 1 and 2). The influence of exogenous factors such as adjacent economies, labor markets, and demographics are factored into the analysis by inclusion of the distance to a major metro city (Tuscaloosa, Meridian, or Montgomery). As in other studies, heterogeneity and exogenous biases in the models are controlled by inclusion of the initial conditions of endogenous factors. Inclusion of both initial and changed conditions of the control variables help show whether the income change was a result of initial conditions, some changes of the condition, or both (Sala-i-Martin, 1996).

A bivariate correlation matrix was used to select relevant variables. When two variables were highly correlated ( $r \geq 0.60)$, only one was selected (Marcouiller, Kim, and Deller, 2004). For instance, a population density variable was included instead of the highly correlated $(r=0.81)$ urban places variable. Similarly, employment in manufacturing jobs was selected instead of overall employment $(r=0.61)^{6}$

\subsection{Estimation of Regression Models}

The convergence model was estimated in a three-step process. First, the absolute and conditional income convergence models were estimated using an Ordinary Least Squares (OLS) regression model. Second, the OLS residuals were diagnosed for multicollinearity, heteroskedasticity, and spatial dependence effects. Third, based on the results of the diagnostics, spatial autoregressive (spatial lag, spatial error, and spatial cross-regressive) models were estimated. The dependent variables in all models were the natural logs of the ratios of per capita income in 2000 to real (in year 2000 dollars) per capita income in 1980 for each CBG. All explanatory variables were standardized using log-transformations.

\footnotetext{
${ }^{5}$ For details information on normalization process, please visit http://www.geolytics.com/USCensus, 1980_in_2000_Boundaries,Products.asp

6 Data for manufacturing jobs and firms were obtained from National Historical Geographic Information System (Minnesota Population Center, 2004).
}

(C) Southern Regional Science Association 2010. 
TABLE 1. Descriptive Statistics of the Major Socioeconomic Characteristics of the Study Region for 1980 and 2000 (N = 161 CBGs)

\begin{tabular}{|c|c|c|c|c|c|c|c|c|}
\hline \multirow[b]{2}{*}{ Attributes } & \multicolumn{2}{|c|}{ Minimum } & \multicolumn{2}{|c|}{ Maximum } & \multicolumn{2}{|c|}{ Mean } & \multirow{2}{*}{$\begin{array}{c}\text { Mean } \\
\text { Difference }^{1}\end{array}$} & \multirow{2}{*}{$\begin{array}{c}\% \\
\text { Change }^{2}\end{array}$} \\
\hline & 1980 & 2000 & 1980 & 2000 & 1980 & 2000 & & \\
\hline Total population** & 433 & 314 & 2,555 & 2,459 & 1,033 & 928 & -105 & -10.164 \\
\hline Population density & 0.009 & 0.006 & 15.703 & 9.696 & 1.09 & 0.835 & -0.255 & 23.394 \\
\hline White $\% *$ & 8.430 & 0.000 & 94.440 & 99.090 & 38.200 & 33.590 & -4.610 & -12.068 \\
\hline African-American $\%$ & 5.062 & 0.908 & 91.370 & 100.000 & 61.477 & 65.401 & 3.924 & 6.382 \\
\hline Dependent & & & & & & & & \\
\hline population $\% * * *$ & 23.460 & 4.357 & 36.587 & 40.633 & 30.195 & 24.800 & -5.395 & -17.867 \\
\hline Manufacturing & & & & & & & & \\
\hline firms $\%$ & 16.400 & 9.801 & 41.801 & 29.901 & 21.101 & 14.800 & -6.301 & 29.861 \\
\hline Manufacturing jobs $\%$ & 9.532 & 0.00 & 29.580 & 29.703 & 18.860 & 15.160 & -3.70 & -19.618 \\
\hline College & & & & & & & & \\
\hline education $\% * * *$ & 2.137 & 0.00 & 22.180 & 56.098 & 9.889 & 11.962 & 2.073 & 20.963 \\
\hline Per capita income ${ }^{2 *}$ & 4,452 & 4,814 & 19,917 & 42,986 & 9,834 & 13,094 & 3,260 & 33.150 \\
\hline $\begin{array}{l}\text { State per capita } \\
\text { income }\end{array}$ & & & & & 13,518 & 18,189 & 4,671 & 34.553 \\
\hline $\begin{array}{l}\% \text { of population } \\
\text { below poverty*** }\end{array}$ & 6.790 & 0.000 & 64.064 & 73.821 & 36.762 & 31.642 & -5.12 & -13.927 \\
\hline Distance to city (mi.) & 16. & 711 & & 835 & 44 & & -- & -- \\
\hline
\end{tabular}

4.1.1 OLS Model Specification. Initially, a univariate $\beta$-convergence model was estimated to determine if there was absolute income convergence over the 20-year period (Sala-i-Martin, 1996).

$$
\ln \left(\frac{y_{t}}{y_{t-1}}\right)=\alpha+\beta_{0}\left(\ln y_{t-1}\right)+\varepsilon,
$$

where $y_{t}$ is per capita income at the end of the study period and $y_{t-1}$ is per capita income at the beginning of the study period. $\beta_{0}$ is an unknown parameter of interest that measures the level of absolute convergence at $t-1$.

A negative estimate $\left(\beta_{0}\right)$ of the initial per capita income in a univariate regression model is evidence of absolute income convergence. Alternatively, absolute income convergence may not be possible because of variations in units' steady state levels (Sala-i-Martin, 1996). Differences in demographics, employment opportunities, human capital, industry structures, and other factors may preclude units from having identical paths and lead to unbalanced growth in the region. That is, the income growth process may be conditioned by these factors and so a conditional income convergence model has to be estimated (Barro and Sala-i-Martin, 1991; Salai-Martin, 1996). Such a model is:

(C) Southern Regional Science Association 2010. 
TABLE 2. Description of the Variables used and the Expected Relationship between Dependent, Independent, and Control Variables for 1980 and 1980-2000

\begin{tabular}{|c|c|c|c|}
\hline Variables & Description & $\begin{array}{c}\text { Variable } \\
\text { Type }\end{array}$ & $\begin{array}{c}\text { Expected } \\
\text { Relationship }\end{array}$ \\
\hline$\triangle P C I$ & $\begin{array}{l}\text { Natural logs of the ratios of a CBG's PCI in } 2000 \text { to } \\
\text { its } 1980 \mathrm{PCI} \text { in } 2000 \$\end{array}$ & Dependent & \\
\hline$I N C_{1980}$ & Natural log of a CBG's 1980 PCI in $2000 \$$ & Independent & - \\
\hline POPDEN & Number of persons in a CBG per acre & Control & + \\
\hline$A A$ & $\%$ of population in a CBG African-American in 1980 & Control & + \\
\hline$D E P$ & $\%$ of CBG's population in 198015 years or younger & Control & - \\
\hline EDUC & $\begin{array}{l}\% \text { of CBG's population } \geq 25 \text { years old with } \\
\text { bachelor's degree in } 1980\end{array}$ & Control & + \\
\hline EMP & $\begin{array}{l}\% \text { of a CBG's working-age population in } \\
\text { manufacturing jobs in } 1980\end{array}$ & Control & + \\
\hline$I N D$ & $\%$ of county's firms in manufacturing sector in 1980 & Control & + \\
\hline DIST & $\begin{array}{l}\text { Distance (miles) between a CBG and a nearest } \\
\text { central city }\end{array}$ & Control & - \\
\hline$\triangle P O P D E N$ & Change in population density, $1980-2000$ & Control & + \\
\hline$\triangle A A$ & Change in $\%$ of AA population, $1980-2000$ & Control & + \\
\hline$\triangle D E P$ & Change in \% of young population, $1980-2000$ & Control & - \\
\hline$\triangle E D U C$ & $\begin{array}{l}\text { Change in the } \% \text { of bachelor degree holder } \\
\text { population, } 1980-2000\end{array}$ & Control & + \\
\hline$\triangle E M P$ & Change in the $\%$ of manufacturing jobs, $1980-2000$ & Control & + \\
\hline$\triangle I N D$ & Change in the $\%$ of manufacturing firms, $1980-2000$ & Control & + \\
\hline
\end{tabular}

$$
\ln \left(\frac{y_{t}}{y_{t-1}}\right)=\alpha+\beta_{0}\left(\ln y_{t-1}\right)+\beta_{i}\left(X_{i, t}-X_{i, t-1}\right)+\beta_{j} X_{j}+\varepsilon,
$$

where $y_{t}$ is per capita income at the end of the study period and $y_{t-1}$ is per capita income at the beginning of the study period; $\beta_{0}$ is a vector of the log of initial per capita income at time $t-1 ; \beta_{i}$ is a vector of unknown parameters associated with the change in $X_{i}$ variables (such as population density, race, education, etc.); $X_{j}$ is a vector of the initial conditions (of population density, race, education, etc.) of control variables; $\beta_{j}$ is a vector of unknown parameters associated with $X_{j}$ variables; and $\varepsilon_{t}$ is a vector of error terms.

4.1.2 Spatial Model Specification. The socioeconomic and geographic characteristics of states, counties, or Census Block Groups are not entirely independent of the influences of their neighbors. Such interactive effects increase the likelihood that CBGs that share a common boundary have similar socioeconomic characteristics. In the presence of such spatial dependence, OLS regression models (Equation 2) result in biased and inconsistent estimates of conditional convergence. Anselin (1988) and others (Rey and Montouri, 1999; Lall and Yilmaz, 2001; Lim, 2003; Janikas and Rey, 2005) suggest that spatial autoregressive models (spatial lag, spatial error, and cross-regressive models) can be used to control for potential bias in the magnitude of convergence coefficients. Anselin's (2003) and Lim's (2003) guidelines were followed in determining which spatial autoregressive model is suitable for analysis. The spatial lag model (Equation 3) was chosen because the spatial dependence was diagnosed. Spatial effects from

(C) Southern Regional Science Association 2010. 
adjacent CBGs were controlled by inclusion of a spatial lag variable in the conditional income convergence model (Equation 2).

$$
\begin{aligned}
& \ln \left(\frac{y_{t}}{y_{t-1}}\right)=\alpha+\beta_{0}\left(\ln y_{t-1}\right)+\rho W\left(\frac{y_{t}}{y_{t-1}}\right)+\beta_{i}\left(X_{i, t}-X_{i, t-1}\right)+\beta_{j} X_{j}+\varepsilon_{t}, \\
& \varepsilon \sim N\left(0, \sigma^{2} I\right),
\end{aligned}
$$

where scalar $\rho$ is the spatial lag coefficient to be estimated, $W$ is the weights matrix, which is row-standardized, and $\varepsilon$ is a vector of error terms. In other words, $W\left(y_{t} / y_{t-1}\right)$ is the weighted average of ratio of per capita income at period $t$ and $t-1$ of all the adjacent CBGs. The weight matrix $W$ is based on the first order binary "rook contiguity" ( 0 if non-contiguous and 1 if contiguous). ${ }^{7}$ The binary contiguity matrix is row-standardized (as the default in GeoDa) so that the dependent variable (income growth) multiplied by $W$ is a spatial lag estimate (Anselin, 2003).

\section{RESULTS AND DISCUSSION}

\subsection{Estimation of Absolute Convergence}

The absolute income convergence model (Equation 1) was significant $(F=16.994$, $p \leq 0.001$ ), but explained only 9 percent (adjusted $R^{2}=0.091$ ) of the total variation. The convergence coefficient ( $\beta$ value) was negative $(-0.145)$ and significant $(t=-9.891)$ indicating convergence of per capita incomes across the CBGs in the region. The convergence rate is estimated to be 0.5 percent per year, ceteris paribus. ${ }^{8}$ The low $R^{2}$ value indicates that a large amount of the variation in average per capita income convergence is unexplained by the model. The low value also indicates that income growth may be conditional and the convergence can be explained by other factors that control for the differences in steady state points for different regions (Rey and Montouri, 1999).

\subsection{OLS Estimation of Conditional Convergence}

Re-estimation of the convergence model (Equation 2) by inclusion of both initial and changed conditions of control variables proved significant $(F=14.432, p \leq 0.001)$. The independent variables explain 54 percent of the total variation (adjusted $R^{2}=0.543$ ) in per capita incomes between 1980 and 2000 (Table 3, Column 2). The coefficient for the initial per capita income level $\left(I N C_{1980}\right)$ is negative $(\beta=-0.201)$ and significant $(t=-3.817)$, confirming that there was conditional income convergence over the 20 -year period. The estimated rate of income convergence was 1.1 percent per year. This convergence varied across the region based on the initial and changed conditions of the control variables.

Six of the 13 control variables were significant $(p \leq 0.1)$. Population density (POPDEN) and African-Americans (AA) in 1980 had significant negative coefficients. Four change variables were significant at the 1 percent level: race $(\triangle \mathrm{AA})$, share of population under age 15 $(\triangle D E P)$, education $(\triangle E D U C)$, and manufacturing jobs $(\triangle E M P)$. The per capita income growth rate was

\footnotetext{
${ }^{7}$ The weight matrix and spatial models were estimated in GeoDa0.9.5-i5. Geoda (https://www.geoda.uiuc.edu/) is widely used spatial software to examine spatial structure and relationship in the data. The software was designed by Dr. Luc Anselin, professor in the Department of Geography, University of Illinois Urbana-Champaign. The software was made available for public use in 2003.

${ }^{8}$ The convergence rate is calculated using $\theta=-\ln (\beta+1) / t$, where $\mathrm{t}(=20)$ is the number of years in the time period and $\beta$ is the coefficient (Rey and Montouri, 1999; Lim, 2003).
}

(C) Southern Regional Science Association 2010. 
TABLE 3. Results of the Ordinary Least Squares (OLS) and Spatial Lag Models to Predict Income Convergence between 1980 and 2000 in the West-Central Region of Alabama

\begin{tabular}{|c|c|c|c|c|}
\hline \multirow[t]{2}{*}{ Variables } & \multicolumn{2}{|c|}{ OLS model } & \multicolumn{2}{|c|}{ Spatial lag model } \\
\hline & $\beta$ - coefficient & $t$-statistic & $\beta$ - coefficient & $Z$-value \\
\hline Constant & $0.261 * * *$ & 13.943 & 0.206 & 6.867 \\
\hline Per Capita Income 1980 & $-0.201 * * *$ & 3.817 & $-0.194 * * *$ & 3.912 \\
\hline Income Convergence Rate & $1.123 \%$ & & $1.081 \%$ & \\
\hline$\rho$ (spatial lag) & & & $0.218^{* *}$ & 2.324 \\
\hline \multicolumn{5}{|l|}{ A. Initial Conditions (in 1980) } \\
\hline Population Density (POPDEN) & $-0.061 * *$ & 2.387 & -0.033 & 1.274 \\
\hline Blacks $(A A)$ & $-0.093 * * *$ & 2.711 & $-0.085 * * *$ & 2.649 \\
\hline Dependent Population $(D E P)$ & -0.049 & 1.495 & $-0.054 *$ & 1.727 \\
\hline College Education $(E D U)$ & -0.005 & 0.156 & -0.005 & 0.154 \\
\hline Manufacturing Jobs (EMP) & 0.027 & 1.041 & 0.028 & 1.128 \\
\hline Manufacturing Firms (IND) & -0.005 & 0.193 & -0.011 & 0.412 \\
\hline Distance to a Major City (DIST) & -0.006 & 0.259 & -0.011 & 0.465 \\
\hline \multicolumn{5}{|l|}{ B. Changed conditions } \\
\hline Population Density ( $\triangle P O P D E N$ ) & 0.019 & 0.817 & 0.015 & 0.689 \\
\hline Blacks $(\triangle \mathrm{AA})$ & $-0.104 * * *$ & 4.939 & $-0.104 * * *$ & 5.251 \\
\hline Dependent Population ( $\triangle \mathrm{DEP})$ & $-0.081 * * *$ & 3.862 & $-0.085^{* * *}$ & 4.316 \\
\hline College Education ( $\triangle E D U C)$ & $0.083 * * *$ & 3.591 & $0.081 * * *$ & 3.714 \\
\hline Manufacturing Jobs $(\triangle E M P)$ & $0.058 * * *$ & 2.647 & $0.058 * * *$ & 2.801 \\
\hline Manufacturing Firms $(\triangle I N D)$ & -0.005 & 0.211 & -0.017 & 0.647 \\
\hline F-value & $14.432 * * *$ & & & \\
\hline Log Likelihood & 10.536 & & 12.589 & \\
\hline$R^{2}$ (Unadjusted) & 0.581 & & 0.595 & \\
\hline$R^{2}$ (Adjusted) & 0.543 & & -- & \\
\hline Akaike Information Criterion (AIC) & 8.927 & & 6.820 & \\
\hline Multicollinearity Condition & 6.685 & & -- & \\
\hline \multicolumn{5}{|l|}{ Number } \\
\hline Koenker-Bassett Test & $\begin{array}{c}19.639 \\
p=0.141\end{array}$ & & & \\
\hline \multirow[t]{2}{*}{ White Test } & 118.363 & & & \\
\hline & $p=0.499$ & & & \\
\hline \multicolumn{5}{|l|}{ Diagnostics for Spatial Dependence } \\
\hline \multirow[t]{2}{*}{ Moran's I (Error) } & 0.064 & & & \\
\hline & $p=0.018$ & & & \\
\hline \multirow[t]{2}{*}{ Lagrance Multiplier (LM-LAG) } & 3.557 & & & \\
\hline & $p=0.051$ & & & \\
\hline Robust LM (Lag) & $2.213(0.136)$ & & & \\
\hline Lagrance Multiplier (LM-ERROR) & $1.629(0.201)$ & & & \\
\hline Robust LM (ERROR) & $0.285(0.593)$ & & & \\
\hline Likelihood Ratio Test & & & $\begin{array}{c}4.106 \\
(p=0.042)\end{array}$ & \\
\hline
\end{tabular}

Notes: ${ }^{* * *}=p \leq 0.01,{ }^{* *}=p \leq 0.05,{ }^{*}=p \leq 0.1$

(C) Southern Regional Science Association 2010. 
negatively correlated with population density (POPDEN) and African-Americans (AA) in 1980, and change in dependent population $(\triangle D E P)$ and change in African-American population $(\triangle A A)$ between 1980 and 2000. This result is an indicator of a higher level of income growth in areas with low population density $\left(\beta_{i}=-0.061\right)$ and a lower percentage of African-Americans $\left(\beta_{i}=\right.$ $0.093)$ in 1980. Similarly, areas with higher income growth rates had declining AfricanAmerican populations $\left(\beta_{\mathrm{j}}=-0.104\right)$ and declining dependent populations $\left(\beta_{j}=-0.081\right)$. In essence, these findings indicate that higher levels of income growth occurred in the more sparsely populated areas, in predominantly non-African-American areas of the region, and in areas where the African-American population was in decline over the 20 -year period. Conversely, declining or lower levels of income growth were more evident in the more densely populated, predominantly African-American areas, and/or where there were increases in African-American populations (Figures 2 and 3).

Areas with increased manufacturing jobs $\left(\beta_{j}=0.058\right)$ and college graduates $\left(\beta_{\mathrm{j}}=0.083\right)$ were also more likely to have experienced higher income growth. On the other hand, areas with little improvement in higher education levels and negative or low levels of job growth in the manufacturing sector were found to have relatively lower income growth. These results are consistent with Lim (2003) and Henry, Barkley, and Li (2004).

\subsection{OLS Residual Diagnostics}

Diagnostic tests for multicolliniearity, heteroskedasticity, and spatial correlation are presented in Table 3. The OLS model is free of multicolliniearity and heteroskedasticity as is evident from the low multicolliniearity condition number (MCN) of $6.685,{ }^{9}$ a nonsignificant Koenker-Bassett test $(19.639, D F=14, p=0.141)$, and the White test $(118.363, D F=119$, $p=0.499)$. Inclusion of control variables prevented the estimates of the model from uncontrolled heterogeneity. Inclusion of initial levels of the control variables also helped reduce the source of endogeneity bias (Sala-i-Martin, 1996).

The specification test for spatial dependence was conducted following the recommendations by Anselin (2003). The coefficients for the Lagrange Multiplier Test for spatial lag dependence (LM-LAG) is significant $(3.557, p \leq 0.05)$ and spatial error (LM-ERR) is not significant $(1.629, p \geq 0.20)$ at the 5 percent level. ${ }^{10}$ In this situation, the spatial lag dependence model is appropriate; therefore, the OLS estimation is misspecified. In order to obtain consistent and unbiased estimates, a spatial lag model was estimated (Anselin, 2003; Lim, 2003).

\subsection{Spatial Lag Model Estimation of Conditional Income Convergence}

A spatial lag model (Equation 3) was estimated by incorporating a spatially weighted lag variable of per capita income growth (the dependent variable). The results are reported in columns 4 and 5 of Table 3. The model was significant (likelihood ratio test $=4.106, p \leq 0.05$, unadjusted $R^{2}=0.595$ ). The model is a slight improvement compared to the OLS model, as indicated by a decline in Akaike Information Criterion (AIC) to 6.820 from the AIC value of

\footnotetext{
${ }^{9} \mathrm{~A}$ MCN below 30 indicates there is little evidence of multicollinearity, which is acceptable (Anselin 2003).

10 Anselin (2003) suggests assessing the LM-LAG and LM-ERR values to decide which spatial autoregressive model is appropriate. When the LM-LAG coefficient is significant and LM_ERR is not significant, the spatial lag model will be appropriate to choose, and vice versa.
}

(C) Southern Regional Science Association 2010. 


\section{FIGURE 2. Distribution of African-American and White Population in 161 Census Block Groups.}

(a) Race in 1980

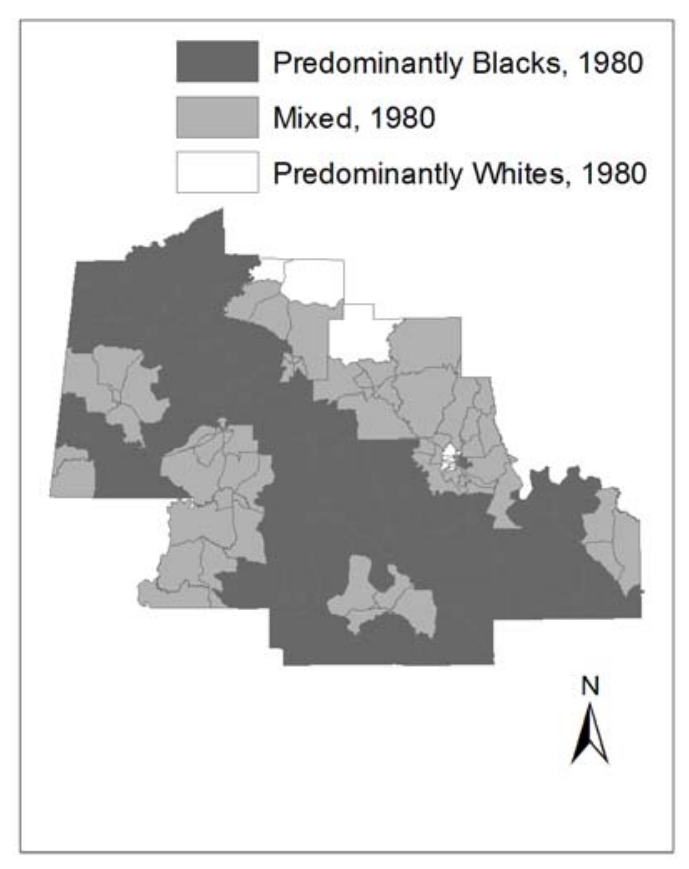

b) Race in 2000

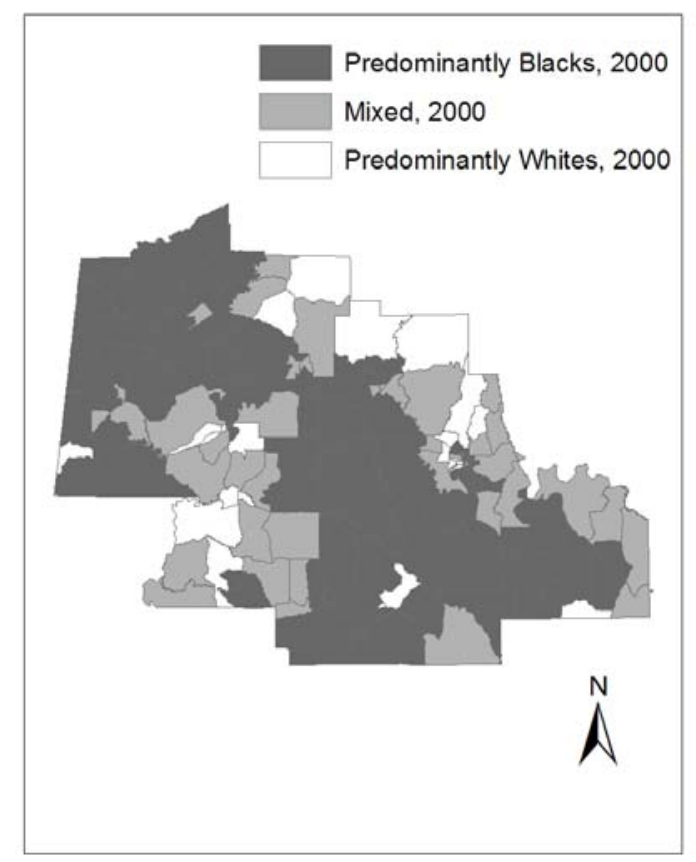

(c) Race Change

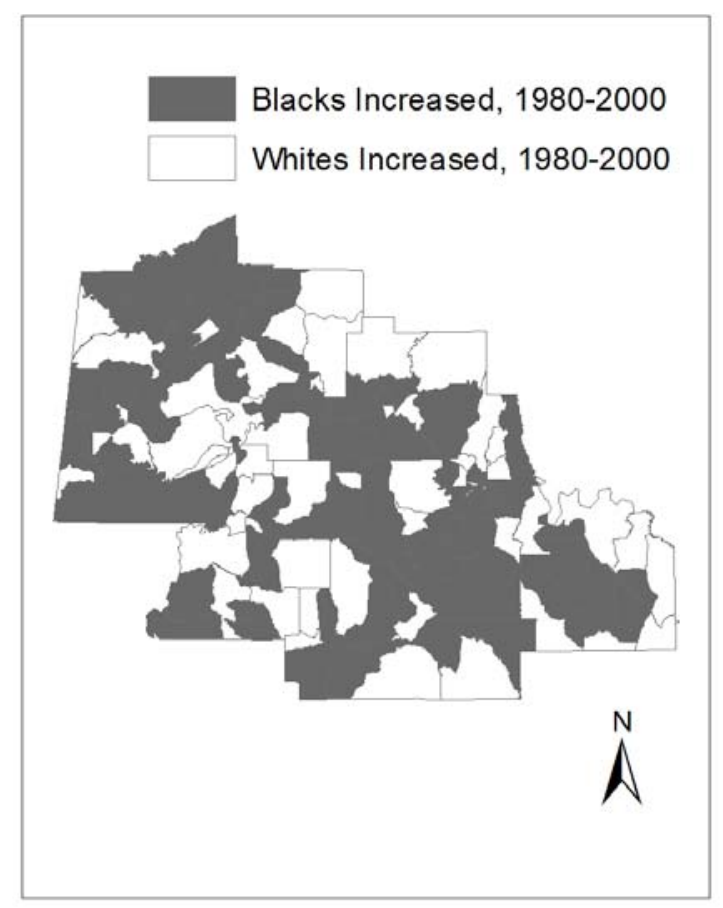

(C) Southern Regional Science Association 2010. 
FIGURE 3. Per Capita Income (PCI) Distribution in 161 Census Block Groups

(a) PCI in 1980

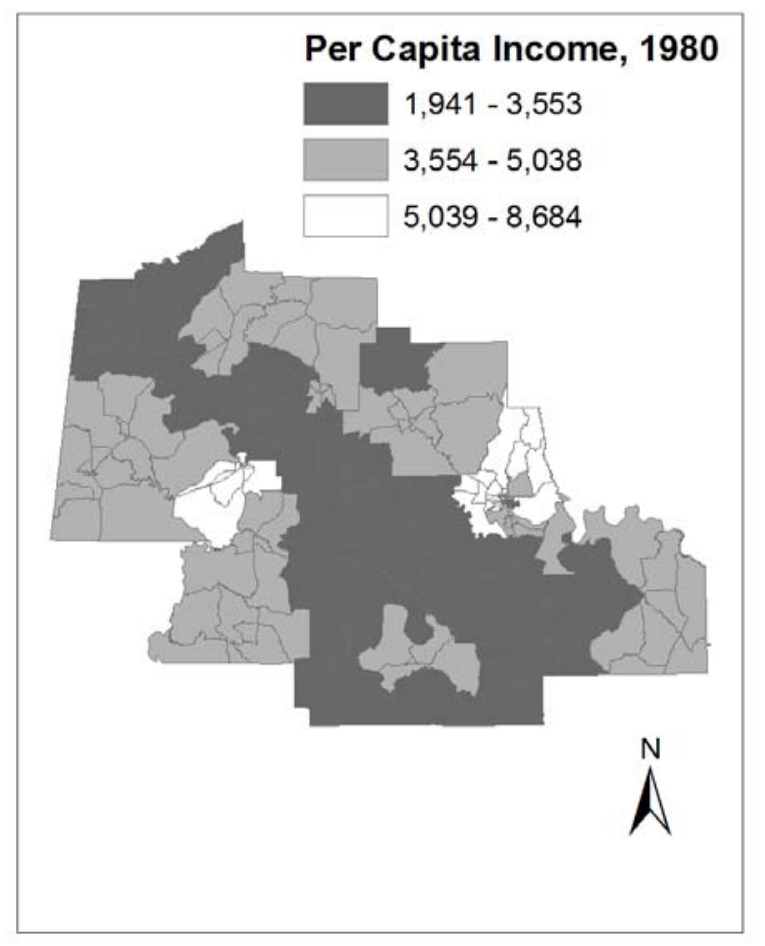

(c) PCI Change

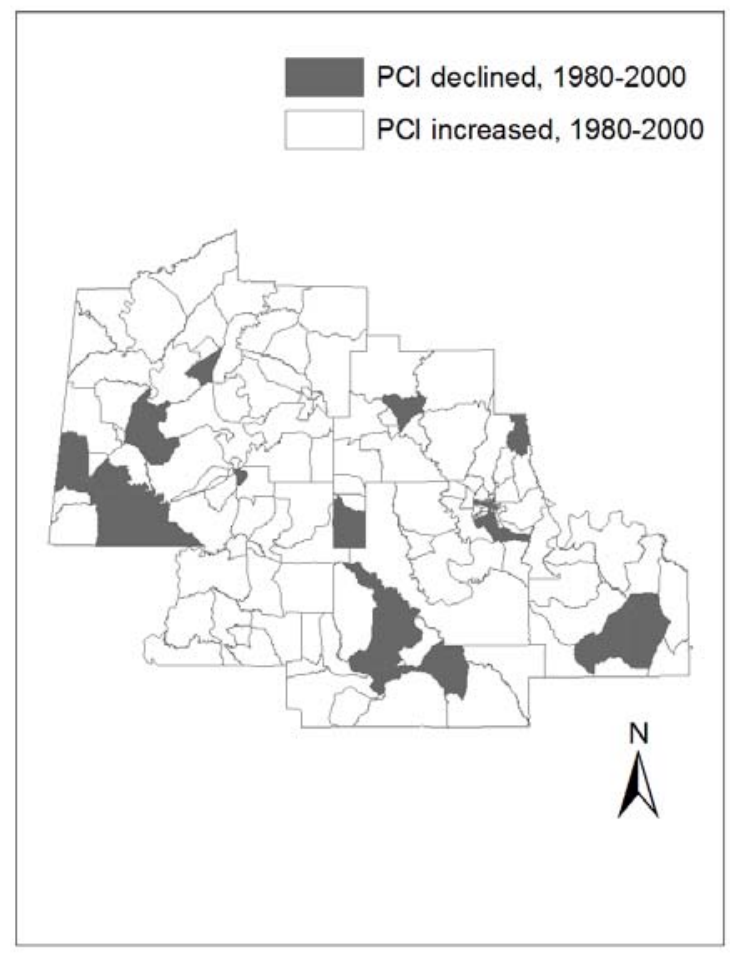

(b) PCI in 2000

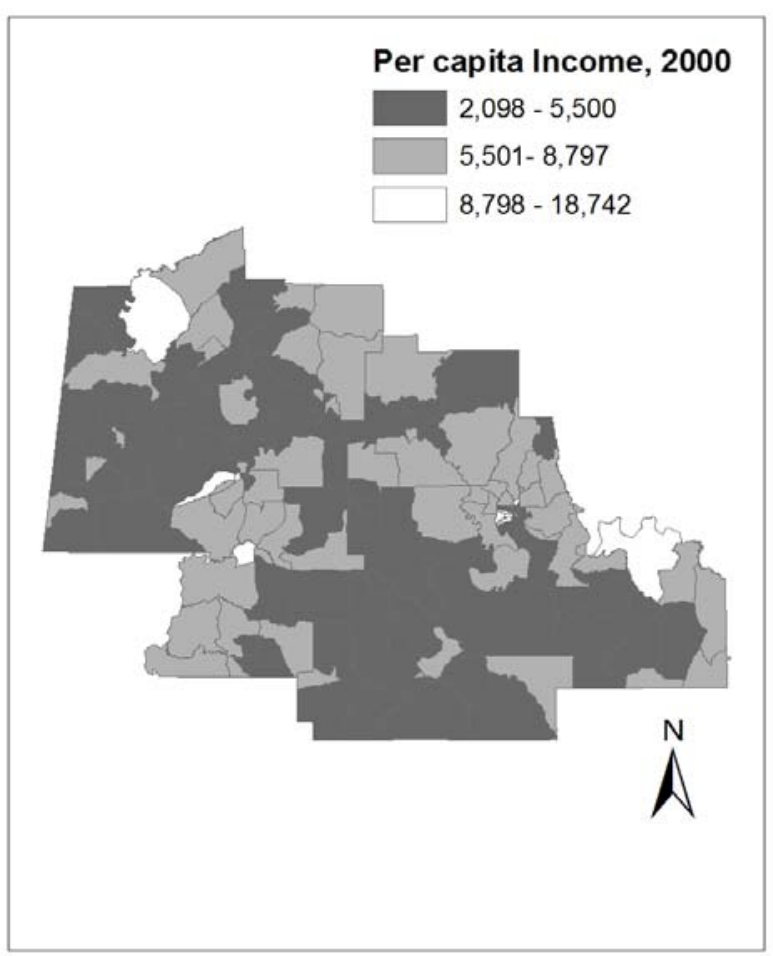


8.927 in the OLS model. ${ }^{11}$ The spatial lag $(\rho)$ estimate was positive $(0.218)$ and significant $(\mathrm{t}=2.324, p<0.05)$ indicating a positive neighborhood effect. In other words, the expected value of a CBG's income growth rate is not only related to its own initial income level and control variables, but also to the effects of the geographic spillovers of the income growth from adjacent CBGs.

The estimate of the income convergence rate obtained from the spatial lag model (1.08 percent) was less than the estimate based on the OLS model (1.123 percent). The difference is a reflection of the spillover effects from adjacent CBGs. Five of the six significant variables from the OLS model were also significant in the spatial lag model. The signs and the significance of the variables in the spatial lag estimation follow similar patterns of OLS. The initial condition of population density (POPDEN) was significant in the OLS model, but not significant in the spatial lag model. Instead, the initial condition of young population (DEP), which was not significant in OLS model, was significant in the spatial lag model. This suggests that the CBGs with the higher percentage of dependent population in 1980 had lower income growth. This also suggests that when income change in adjacent CBGs was considered, the initial population density was not as important as initial population of young people.

The spatial lag model was further examined to detect any significant presence of spatial dependence. The likelihood ratio test value of the spatial lag model was significant $(P<0.05)$, which suggests that there are spatial spillover effects of independent variables (Lim, 2003). As noted by Anselin (2003), the omission of such cross-lag terms would lead to spatially autocorrelated errors. The spatial cross-regressive model was used to test whether or not there is any remaining spatial dependence in the relationship (Lim, 2003).

The spatial cross-regressive estimation, i.e., addition of the spatial lag-effect variables to the OLS model, slightly increased the unadjusted $R^{2}$ from 0.543 to 0.563 . The AIC value (12.351) of the spatial cross-regressive model was higher than the AIC values of the OLS (AIC= $8.927)$ and the spatial lag model $(A I C=6.820)$. This suggests that the spatial cross-regressive model did not perform any better than the spatial lag model in explaining the total variations in income growth. ${ }^{12}$

\section{DISCUSSION}

This empirical examination of the income growth mechanism and its pathways was approached in an innovative way by using data available at a finer geographic scale in a rural area noted for endemic poverty. This study went beyond prior empirical studies in examining income convergence and the contribution of effects of race, population structure, education, industrial jobs, and spatial effects, which are often cited as important determinants of income growth. The results revealed that a negative and significant association between per capita income growth and the initial level of income is evidence of convergence in income over the 20year period. However, absolute income convergence in the study region was weak and this

\footnotetext{
${ }^{11}$ The $R^{2}$ and $\log$ likelihood values increase when more variables are added in the regression model. The $A I C$ correctly adjusts the log likelihood for overspecification of the model. $A I C$ is calculated as $A I C=-2 L+2 K$, where $L$ denotes the maximized log likelihood and $K$ is the number of variables (Lim, 2003).

12 The Geoda 0.9.5-i5 software does not estimate the adjusted $R^{2}$ values of the spatial lag model; therefore it cannot be used for comparison with the OLS or spatial cross-regressive models. Instead, the AIC values can be used to examine which model (OLS, spatial lag or spatial cross-regressive) provides the best estimates (Anselin, 2003). The spatial lag model provided the best estimates as its AIC value was the lowest one. Therefore, we only reported and used the results from the OLS and spatial lag models for further discussion.
}

(C) Southern Regional Science Association 2010. 
suggested conditional income convergence and evidence of other factors affecting the path of convergence.

The results of the spatial lag model provided the best estimates of per capita income growth and strong evidence of spatial clustering in income convergence. Results of the spatial lag model indicated that CBG-level data are more uniform and relatively less influenced by the exogeneity found in other studies that used county or larger areas as the unit of analysis (Crown and Wheat, 1995; Latzko, 2002; Rupasingha, Goetz, and Freshwater, 2002; Rey and Montouri, 1999). In fact, the income convergence process in the study region is a function of the relatively higher influence of CBG-specific endogenous conditions. That is, the region appears to be economically isolated from exogenous influences.

The negative relationship between initial per capita income and per capita income growth suggests that incomes in the less wealthy CBGs increased at higher rates than their wealthier counterparts over the 20 -year period. Based on the spatial lag model, the estimated catch-up rate of income convergence was an average of 1.081 percent per year. This rate means a more economically homogeneous region is gradually evolving in the study area, a finding consistent with neoclassical growth theories. The relatively low convergence rate is consistent with the gloomy picture painted by the Black Belt Commission (Riley, Ivey, and Sanders, 2005) and found in other studies (Joshi, Bliss, and Bailey, 2000). These findings support calls for strong and diversified economic policies in the region if higher rates of income growth are to be achieved.

There is compelling evidence of the significant effects of race, human capital, and manufacturing employment on per capita income growth. The racial effect was localized; income growth was low in CBGs with high African-American populations in 1980 as well as where the changes in African-American population were high. Conversely, CBGs with higher percentages of other (predominantly white) populations in 1980 and lower changes in African-Americans had higher income growth over the 20 -year period.

There were positive effects from human capital improvements and increasing manufacturing jobs. More precisely, CBGs with increasing educational attainment and a higher number of manufacturing jobs over the period experienced higher income growth. These results revealed the potentially positive impact of improved college education and increasing manufacturing employment as a result of state, federal and private education and employment initiatives (Riley, Ivey, and Sanders, 2005). The results are also consistent with Mykerezi and Mills (2004) findings that there are higher aggregate returns on new investments in postsecondary education. The positive income effects of an increased percentage of college or higher degree graduates is consistent with the nationwide growth in the income gap between college graduates and non-college graduates (Pritchett, 1996; Henry, Barkley, and Li, 2004; Albrecht, Albrecht, and Murguia, 2005).

The effects of race and population structure on income growth were endogenous. Change in income was significantly affected by racial composition and young age structure of the population. On the other hand, the effects of education and manufacturing jobs were exogenous since their initial conditions were not significant.

The non-significance of the population density variable suggests that there is no significant difference in income change between town centers and rural areas within the region. Also, the non-significant contribution of manufacturing firms may indicate that these firms are

(C) Southern Regional Science Association 2010. 
not the major source of income for local communities. The declining number of manufacturing industries and their instability in rural areas since the 1980s supports the result (Drennan, Tobier, and Lewis, 1996; Albrecht, Albrecht, and Murguia, 2005). Similarly, the non-significance of commuting distance suggests that proximity to a major city was not important. In other words, external geographic spillover from the metro areas was not a factor and income growth in a CBG was more influenced by neighboring CBGs than by larger metropolitan areas adjacent to the region.

\section{CONCLUSION}

The major thrust of this paper is understanding income convergence between 1980 and 2000 in a poor, majority-minority, nonmetropolitan region using sub-county level data. The results reveal income convergence in the 161 CBGs. Incomes have grown at higher rates in CBGs with lower income levels in 1980. This convergence was not absolute, but influenced by initial size and change in the percentage of African-Americans and dependent population as well as changes in the human capital and manufacturing jobs in a CBG over the 20-year period.

The results have three policy implications. First, despite being the majority population in each of these eight contiguous counties and a two-thirds majority in the region as a whole, African-Americans and predominantly African-American areas have not seen the progress that European-Americans have experienced in the 20-year period. Second, aside from race, other important factors were at play: (1) population structure and stability, (2) manufacturing jobs, (3) educational attainment, and (4) spatial effects. Third, the model explained 60 percent of the income changes while other variables thought to be significant (e.g. population density and manufacturing firms) were shown to be of less importance than were the effects from metropolitan areas.

The focus of future economic development in this region should be the creation of employment and higher education opportunities for the more densely populated areas, especially predominantly African-American areas with lower income levels. Development of outreach and training activities and value-added production may increase earning opportunities and help them to catch up to the level of incomes of other populations.

This paper has also shed some methodological insight on the importance of disaggregated data at a finer geographic scale in the examination of economic growth. The results indicate that policy interventions based on the broad income growth models estimated at larger geographic scales may overshadow or do not fully recognize the needs of the most marginalized communities, such as minorities in nonmetropolitan counties (Rupasingha, Goetz, and Freshwater, 2002; Crandall and Weber, 2004). This study's approach of examining income convergence at a finer geographic scale while considering both the initial levels and the change in the control variables may have provided a more realistic assessment of income growth. Regional growth models built by aggregating models based on lower-level (e.g. CBG) data can better help policy makers understand the influences of endogenous socioeconomic and geographic factors. This assertion will be more valid when researchers consider scaling up this methodology into larger and more diverse geographic areas (such as state or regional levels). Such efforts would provide more dependable insight into spatial effects and motivate feasible and realistic policies to address economic development in the most impoverished rural places.

(C) Southern Regional Science Association 2010. 


\section{REFERENCES}

Aghion, Philippe and Peter Howitt. (1997) Endogenous Growth Theory. MIT Press: Cambridge, Massachusetts.

Alabama Forestry Commission (AFC). (2008) Alabama's Primary Forest Industry by County and Company Name. August 6, 2008. Available at http://www.forestry.state.al.us/PDFs/Primary_Forest_Industry_Listing_by_County_and_ Company_Name.pdf, last accessed in January 2010.

Albrecht, Don E. and Carol M. Albrecht. (2007) "Income Inequality: the Implications of Economic Structure and Social Conditions,” Sociological Spectrum, 27, 165-181.

Albrecht, Don E., Carol M. Albrecht, and Edward Murguia. (2005) "Minority Concentration, Disadvantage, and Inequality in the Nonmetropolitan United States," Sociological Quarterly, 46, 503-523.

Anselin, Luc. (1988) Spatial Econometrics: Methods and Models. Kluwer Academic Publishers: Boston, Massachusetts.

- (2003) Geoda 0.9.5-I5 User's Guide. Department of Agricultural and Consumer Economics, University of Illinois: Urbana, Illinois.

Auto Alliance. (2008) "The Jobs the Engine that Drives the Economy," Available at http://www.autoalliance.org/archives/Jobs.pdf, February.

Barro, Robert J. and Xavier X. Sala-i-Martin. (1991) "Convergence across States and Regions," Brookings Papers on Economic Activity, 1, 107-182.

Bathelt, Harald. (2006) "Geographies of Production: Growth Regimes in Spatial Perspective 3Toward a relational View of Economic Action and Policy," Progress in Human Geography, 30, 223-236.

Baumol, William J. (1986) "Productivity Growth, Convergence and Welfare: What the Long Run Data Show," American Economic Review, 76, 1072-1085.

Connaughton, John E. and Ronald A. Madsen. (2004) "Explaining Per Capita Personal Income Differences Between States," Review of Regional Studies, 34, 206-220.

Crandall, Mindy S. and Bruce A. Weber. (2004) "Local Social and Economic Conditions, Spatial Concentrations of Poverty and Poverty Dynamics," American Journal of Agricultural Economics, 86, 1276-1281.

Crown, William H. and Leonard F. Wheat. (1995) "State Per Capita Income Convergence Since 1950 Share Cropping's Demise and Other Influences," Journal of Regional Science, 35, $527-552$.

Drennan, Matthew P., Emanuel Tobier, and Jonathan Lewis. (1996) "The Interruption of Income Convergence and Income Growth in Large Cities in the 1980s," Urban Studies, 33(1), 63-81.

Geolytics, Inc. (2004) U.S. Census DVD Time Series Normalized Research Package Data. Geolytics, Inc.: East Brunswick, New Jersey.

Gibbs, Robert M. and G. Andrew Bernat. (1997) "Rural Industry Clusters raise Local Earnings," Rural Development Perspectives, 12(3), 18-25.

(C) Southern Regional Science Association 2010. 
Goetz, Stephan and Anil Rupasingha. (2002) "High-Tech Firm Clustering: Implications for Rural Areas," American Journal of Agricultural Economics, 84, 1229-1236.

Hammond, George W. (2006) "A Time Series Analysis of U.S. Metropolitan and Nonmetropolitan Income Divergence," Annals of Regional Science, 40, 81-94.

Henry, Mark S., David Barkley, and Haizhen Li. (2004) "Education and Nonmetropolitan Income Growth in the South," Review of Regional Studies, 34, 223-244.

Janikas, Mark V. and Sergio J. Rey. (2005) "Spatial Clustering, Inequality and Income Convergence," Région et Développement, 21, 45-64.

Joshi, Mahendra L., John Bliss, Conner Bailey, Lawrence Teeter, and Keith J. Ward. (2000) "Investing in Industry, Under-Investing in Human Capital: Forest-based Rural Development in Alabama," Society and Natural Resources, 13, 291-319.

Kim, Sukkoo. (1998). "Economic Integration and Convergence: U.S. Regions, 1840-1987," The Journal of Economic History, 58, 659-683.

Lall, Somikand and Serdar Yilmaz. (2001) "Regional Economic Convergence: Do Policy Instruments Make a Difference?," Annals of Regional Science, 35, 153-166.

Latzko, David A. (2002) "Convergence of Income across Pennsylvania Counties," Eastern Economic Journal, 28, 499-508.

Lim, Up. (2003) “A Spatial Analysis of Regional Income Convergence," Planning Forum, 9, 66-80.

Loewy, Michael B. and David H. Papell. (1996) “Are U. S. Regional Incomes Converging? Some Further Evidence," Journal of Monetary Economics, 38, 587-598.

Lopez-Bazo, Enrique, Esther Vaya, and Manuel Artis. (2004) "Regional Externalities and Growth: Evidence from European Regions,” Journal of Regional Science, 44, 43-73.

Lynch, Robert G. (2003) "Estimates of Income and Income Inequality in the United States and in each of the fifty states: 1988-1999," Journal of Regional Science, 43, 571-587.

McLaughlin, Diane K. and Shannon Stokes. (2002) "Income Inequality and Mortality in US Counties: Does Minority Racial Concentration Matter?" American Journal of Public Health, 92, 99-104.

Mankiw, N. Gregory, David Romer, and David N. Weil. (1992) "A Contribution to the Empirics of Economic Growth,” Quarterly Journal of Economics, 107, 407-437.

Marcouiller, David W., Kwang-Koo Kim, and Steven C. Deller. (2004) "Natural Amenities, Tourism and Income Distribution," Annals of Tourism Research, 31, 1031-1050.

Minnesota Population Center. (2004) National Historical Geographic Information System: Prerelease Version 0.1. University of Minnesota: Minneapolis, MN.

Molho, Ian. (1995) "Spatial Autocorrelation in British Unemployment," Journal of Regional Science, 35, 641-658.

Mykerezi, Elton and Bradford Mills. (2004) "Education and Economic Well-Being in Racially Diverse Rural Counties: The Role of Historically Black Colleges and Universities," Review of Regional Studies, 34, 303-319.

(C) Southern Regional Science Association 2010. 
Myrdal, Gunnar. (1957) Economic Theory and Under-Developed Regions. Harper and Row: New York.

Nissan, Edward and George H. Carter. (2005) "Decomposition of Regional Metropolitan and Nonmetropolitan Income Inequality," Journal of Economics and Finance, 29, 73-84.

Ngarambe, Octavian, Stephan. J. Goetz, and David L. Debertin. (1998) "Regional Economic Growth and Income Distribution: County-Level Evidence from the U.S. South," Journal of Agricultural and Applied Economics, 30, 325-337.

Pritchett, Lant. (1996) "Forget Convergence: Divergence Past, Present, and Future," Finance and Development, 33, 50-43.

Rey, Sergio J. and Brett D. Montouri. (1999) “US Regional Income Convergence: A Spatial Econometric Perspective," Regional Studies, 33, 143-156.

Rey, Sergio J. and Mark V. Janikas. (2005) "Regional Convergence, Inequality, and Space," Journal of Economic Geography, 5, 155-176.

Riley, Bob, Kay Ivey, and Hank Sanders. (2005) Black Belt Action Commission. Governor's Commission for Action in Alabama's Black Belt: Montgomery, Alabama.

Rupasingha, Anil, Stephan J. Goetz, and David Freshwater. (2002) "Social and Institutional Factors as Determinants of Economic Growth: Evidence from the United States Counties," Papers in Regional Science, 81, 139-155.

Rural Sociological Society (RSS) Task Force on Persistent Rural Poverty. (1993) Persistent Poverty in Rural America. Westview Press: Boulder, Colorado.

Sala-i-Martin, Xavier X. (1996) "Regional Cohesion: Evidence and Theories of Regional Growth and Convergence," European Economic Review, 40, 1325-1352.

Schelhas, John, Robert Zabawa, and Joseph Molnar. (2003) "New Opportunities for Social Research on Forest Landowners in the South," Southern Rural Sociology, 19(2), 60-69.

Sherwood-Call, Carolyn. (1996) "The 1980s Divergence in State per Capita Incomes: what does it tell us?” Federal Reserve Bank of San Francisco Economic Review, 1, 14-25.

Snyder, Anastasia R., and Diane. K. McLaughlin. (2004) "Female-Headed Families and Poverty in Rural America,” Rural Sociology, 69, 127-149.

Solow, Robert M. (1956) "A Contribution to the Theory of Economic Growth," Quarterly Journal of Economics, 70, 65-94.

Tolnay, Stewart E. (2003) "The African American 'Great Migration' and Beyond," Annual Review of Sociology, 29, 209-232.

United States Census Bureau. (2009) "Census Blocks and Block Groups," Chapter 11 of Geographic Areas Reference Manual. Geography Division, Washington, D.C., http://www.census.gov/geo/www/garm.html, March.

Yamamoto, Daisaku. (2008) "Scales of Regional Income Disparities in the USA, 1955-2003," Journal of Economic Geography, 8, 79-103.

(C) Southern Regional Science Association 2010. 